\title{
The Journal of Plant Pathology launches the Editors' Choice Section
}

(C) Società Italiana di Patologia Vegetale (S.I.Pa.V.) 2019

Starting in 2019, the Journal of Plant Pathology will highlight articles of significant relevance, by including them in the newly created Editors' Choice Section at the beginning of each issue of the Journal of Plant Pathology. Editors' Choice papers describe transformative research in the field of Plant Pathology or provide novel experimental "proof of concept" for any area of the biological sciences focusing on plant disease or on plant-microbe interactions. Editors' Choice papers may also include submissions describing studies on a highly visible subject and/or on extremely timely topics in the field of Plant Pathology. Finally, review articles that fill significant gaps in coverage of current literature or that are meant to update significantly older review articles may also be Editors' Choice papers. Authors are encouraged to indicate whether their submission meets the requirements of an Editors' Choice paper, but the final selection of these papers is an exclusive prerogative of the Journal of Plant Pathology Editorial Board, and is signed off by the Handling Associate and Senior Editors, the Ad Hoc "Editors' Choice" Editor and by the Editor in Chief.

We are pleased to introduce our first Editors' Choice pick in this issue. The article titled "Evidence for inhibition of a fungal biocontrol agent by a plant microbiome" by Garbelotto, Lowell, Chen and Osmundson is a timely study that not only investigates the community composition of epi- and endophytic fungi in an exotic invasive plant, but also experimentally tests the antagonistic effect of such fungi against the fungal pathogen Colletotrichum gloeosporioides f. sp. miconiae artificially introduced as a biocontrol agent. Results were surprising in more than one way: a) the biocontrol agent was found in all plants tested, independent of their location, however infection was not evident at lower elevation; b) the fungal communities at low, intermediate and high elevation were drastically different, even if sites at different elevation were adjacent to one another; c) fungal communities from low elevations were significantly more antagonistic vs. the biocontrol agent, potentially justifying the low efficacy of the biocontrol in low lying sites. The study has applied and theoretical implications: it explains local failure of the biocontrol agent and pressures the research and regulatory community to identify different control approaches, while drawing a very interesting parallel between the roles played by the human and plant microbiomes.

The invasive plant studied was Miconia calvescens, regarded as one of the most significant threats to native habitats in Polynesian islands. The Editors note both the importance of the topic, and the difficulty of performing such a complex study in harsh tropical environments, with minimal preliminary knowledge.

Matteo Garbelotto, Editors' Choice Editor Paolo Gonthier, Handling Senior Editor Giovanni Martelli, Editor in Chief

Publisher's note Springer Nature remains neutral with regard to jurisdictional claims in published maps and institutional affiliations. 